\title{
Storage effects on flour quality of commonly consumed cereals
}

\author{
Preeti Goyal $^{1 *}$, Lakshman Kumar Chugh ${ }^{2}$ and Mukesh Kumar Berwal ${ }^{3}$ \\ ${ }^{1}$ Department of Chemistry and Biochemistry, CCS Haryana Agricultural University, Hisar-125004 (Haryana), INDIA \\ ${ }^{2}$ Pearl Millet Quality Lab, Department of Genetics and Plant Breeding, CCS Haryana Agricultural University, Hi- \\ sar-125004 (Haryana), INDIA \\ ${ }^{3}$ Physiology and Biochemistry Section, ICAR-Central Plantation Crops Research Institute, Kasaragod-671124 (Kerala), \\ INDIA \\ *Corresponding author. E-mail: goyalpreetigoyal@gmail.com
}

Received: June 12, 2016; Revised received: January 8, 2017; Accepted: February 20, 2017

\begin{abstract}
The present investigation was conducted to study the effect of storage period on flour quality of wheat, maize and pearl millet. Their flour were stored at $15{ }^{\circ} \mathrm{C}$ and $82 \%$ relative humidity $\mathrm{RH}$ for one month a nd changes in fat acidity (FA), activities of peroxidase (POX), lipoxygenase (LOX) and polyphenol oxidase (PPO) in control and stored flour along with change in $\mathrm{pH}$ of water extract of flour were monitored. Increase in FA (mg KOH/100 g d.m.) and decrease in $\mathrm{pH}$ of flour was maximal in pearl millet $(287.5 \mathrm{mg} \mathrm{KOH} / 100 \mathrm{~g} \mathrm{~d} . \mathrm{m}$. and 0.4$)$ followed by maize (151 $\mathrm{mg} \mathrm{KOH} / 100 \mathrm{~g} \mathrm{~d} . \mathrm{m}$. and 0.23$)$ and wheat $(61 \mathrm{mg} \mathrm{KOH} / 100 \mathrm{~g} \mathrm{~d} . \mathrm{m}$. and 0.1$)$ respectively. A decline in activity of POX, LOX and PPO was observed during storage. Pearl millet flour possessed almost double activity of POX (413 Units/g d.m.) in comparison to wheat (198 Units/g d.m.) and 1.3 fold higher than that of maize (153 Units/g d.m.) and even after decrease activity of POX was higher in flour of pearl millet compared to the other two. However, activity of LOX and PPO was found to be comparable in fresh flour of pearl millet, maize and wheat. Since pearl millet has poor shelf life and increase in FA, decrease in $\mathrm{pH}$ and activity of POX was found to be very high in pearl millet (poor shelf life) as compared to wheat and maize, therefore, these selected parameters might be used as biochemical markers to determine shelf life of flour.
\end{abstract}

Keywords: Cereal grains flour, Fat acidity, Oxidative enzymes, pH, Shelf-life

\section{INTRODUCTION}

Cereal grains (wheat, maize and pearl millet) flour may be used singly (e.g., wheat bread, frying batters) or in combination (e.g., certain ready to eat breakfast, snack foods, certain breads and others) as source of energy in human diet throughout the world. These cereals can be stored for longer period without deterioration in quality if the kernels remain intact. However, once the grain is ground, the quality of resulting meal deteriorates rapidly due to the presence of lipids and lipid degrading enzymes (Dobaldo-Maldonado et al., 2012). Milling destroys the structure of the seed/kernel by breaking the cell walls. The endosperm loses the protection of the outer layers and is open to attacks by enzymes, microbes, insects, and environmental moisture and gases. Deteriorative processes within flour, free radical generation/oxidation and non-enzymatic glycosylation, fragmentation and/or cross-linking of constitutive proteins, lipids and sugars, subsequently affecting chemical and quality parameters of cereal grains flour and various milling products (Wang and Flores, 1999). The changes which occur in stored flour are probably due to enzymes produced or liberated in the flour (Dobaldo-Maldonado et al., 2012). The fats may be hydrolyzed by lipolytic enzymes. This together with the production or destruction of other acids should manifest itself by a change in hydrogen-ion concentration of the flours. Flour quality could be destroyed totally with prolonged storage. Flour components, such as protein, starch and lipids change and these changes directly affect organoleptic properties. The moisture contents in the grains or humidity and storage temperature have also been shown to cause some changes in the acidity and $\mathrm{pH}$ of the cereals and cereal products (Huyghcbact and Schoner, 1999). High activity of peroxidase and enzyme catalysed changes in phenolics was found to play important role in deterioration of flavour and taste (Bangar et al., 1999; Suzuki et al., 2006). Peroxidase catalyzes peroxidative degradation of unsaturated fatty acids yielding volatile and flavourful carbonyl compounds that may contribute to oxidized flavour (Tiwari et al., 2014). Significant positive correlation $(r=0.999)$ has been reported by Lee and Hammes (1979) between off-flavour development and peroxidase activity in frozen sweet corn. Peroxidase has recently been purified and characterized from pearl millet grains (Goyal and Chugh 2014). Another enzyme lipoxygenase (LOX) catalyses oxidation reaction, which produces medium-chain alde- 
hydes, ketones and their alcoholic counterparts (pentanal, hexanal, heptanal and even nonanal along with their unsaturated forms). Lipoxygenase has been reported to play a major role in deterioration of soybean flour (Dahuja and Madaan, 2003; Mandal et al., 2014). The LOX has not yet been studied from maize and pearl millet. The changes in the chemical composition of flour have made the biochemical and nutritional quality control of the stored products increasingly essential (Rehman, 2006). Keeping this fact in view the present investigation was undertaken to examine the effect of storage period on biochemical quality of wheat, maize and pearl millet (commonly consumed cereal grain) flours and investigate the factors responsible for their deterioration during storage.

\section{MATERIALS AND METHODS}

Mature grains of pearl millet, wheat and maize procured from Department of Genetics and Plant Breeding, CCS HAU, Hisar were used. Flour made of mature grains was stored in aluminium boxes at $15{ }^{\circ} \mathrm{C}$ and $82 \%$ RH. The stored flour of these genotypes was analyzed simultaneously along with the fresh flour prepared on the respective day of storage for the characters mentioned below. All the chemicals used were of high-purity analytical grade.

Biochemical analyses: The fat acidity was expressed as potassium hydroxide required to neutralize the acids in a $100 \mathrm{~g}$ sample using phenolphthalein as an indicator (AACC, 1999). The $\mathrm{pH}$ of water extract of flour was determined by the method of AOAC (1990).

\section{Enzymatic activities}

Preparation of extract: Preliminary experiments were conducted to optimize the extraction conditions with respect to $\mathrm{pH}$, molarity and type of buffer. The primary objective, whatever the grinding procedure, was to effect adequate cell breakage in a minimum amount of time with no warming of the extract. One gram of flour was homogenized in a prechilled pestle and mortar in $10 \mathrm{~mL}$ of $0.2 \mathrm{M}$ potassium phosphate buffer ( $\mathrm{pH} 7.5)$. The homogenate was centrifuged at $10000 \mathrm{rpm}$ for 20 min in a refrigerated centrifuge. The supernatant was carefully filtered through four layers of cheese cloth and used as crude enzyme preparation for determining enzyme activities.

Assay methods: Peroxidase was assayed by the method of Malik and Singh (1980). The assay mixture (2.8 mL) contained: $2.5 \mathrm{~mL}$ of $0.05 \mathrm{M}$ potassium phosphate buffer ( $\mathrm{pH} 6.8), 0.1 \mathrm{~mL} o$-dianisidine $(0.1 \%)$, $0.1 \mathrm{~mL} \mathrm{H}_{2} \mathrm{O}_{2}(0.1 \mathrm{M})$ and $0.1 \mathrm{~mL}$ enzyme preparation (suitably diluted). The reaction was started by adding $\mathrm{H}_{2} \mathrm{O}_{2}$. Omission of $\mathrm{H}_{2} \mathrm{O}_{2}$ from the reaction mixture served as blank. Increase in absorbance was monitored at $430 \mathrm{~nm}$ at an interval of $15 \mathrm{sec}$ for $2 \mathrm{~min}$. Lipoxygenase activity in crude extract was measured spectrophotometrically at $234 \mathrm{~nm}$. Substrate (linoleic acid) was prepared by method of Surrey (1964). The reac-
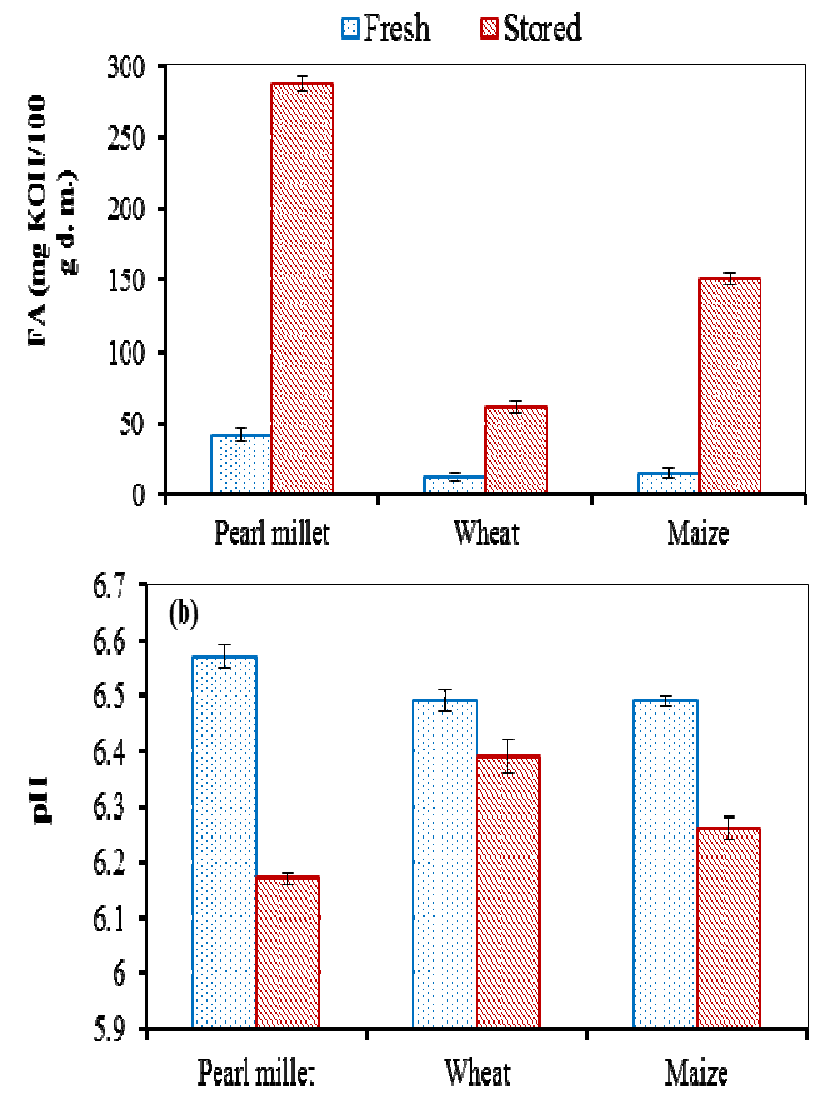

Fig. 1. FA (a) and $p H$ of water extract (b) of fresh and stored flour of pearl millet, wheat and maize.Values are mean $\pm S E$, $n=3$.

tion mixture $(2.66 \mathrm{~mL})$ contained $2.5 \mathrm{~mL}$ of $0.05 \mathrm{M}$ acetate buffer ( $\mathrm{pH} 4.2), 60 \mu \mathrm{l}$ of $7.5 \mathrm{mM}$ linoleic acid and $0.1 \mathrm{~mL}$ (suitably diluted) of enzyme extract. The reaction was started by the addition of enzyme and increase in absorbance at $234 \mathrm{~nm}$ was noted for 2 min against blank. Omission of enzyme from the reaction mixture served as blank. Activity of polyphenol oxidase was determined by the method of Kurger (1976) with minor modifications. A $0.01 \mathrm{M}$ substrate (Catechol) solution was prepared in $0.05 \mathrm{M}$ phosphate buffer, $\mathrm{pH}$ 6.2. This substrate solution was prepared fresh. The reaction was initiated by adding $0.2 \mathrm{~mL}$ of enzyme extract (suitably diluted) to $2.8 \mathrm{~mL}$ of substrate solution at room temperature. This mixture was incubated at $37{ }^{\circ} \mathrm{C}$ for $30 \mathrm{~min}$. The absorbance was measured at $410 \mathrm{~nm}$ on a UV-Vis spectrophotometer. A blank was run simultaneously with boiled enzyme extract. One unit of enzyme activity was defined as the amount of enzyme required to increase 0.1 unit absorbance $\min ^{-1} \mathrm{~g} \mathrm{d.m} .^{-1}$ (dry matter) under the test conditions.

Statistical analysis: Estimation of all the chemical/ biochemical parameters was done in triplicates. The data recorded during the present investigation was statistically analyzed using Statistical Package for Agriculture Scientists', OPSTAT. 


\section{RESULTS AND DISCUSSION}

Biochemical changes responsible for flour deterioration occurred to various extent during storage.

Fat acidity (FA) and pH: It is apparent from the Figure 1a that FA in fresh flour of pearl millet was higher (47.5 mg KOH/100 g d. m. [dry matter]) than that of wheat and maize (12 and $15 \mathrm{mg} \mathrm{KOH} / 100 \mathrm{~g} \mathrm{~d}$. m.) respectively. Significant increase in fat acidity was observed during storage in flour of pearl millet, wheat as well as maize but magnitude of increase was different. It was highest in stored flour of pearl millet (287.5 $\mathrm{mg} \mathrm{KOH} / 100 \mathrm{~g} \mathrm{~d} . \mathrm{m}$.) followed by maize $(151.0 \mathrm{mg}$ $\mathrm{KOH} / 100 \mathrm{~g} \mathrm{~d} . \mathrm{m}$.) and wheat $(61.0 \mathrm{mg} \mathrm{KOH} / 100 \mathrm{~g} \mathrm{~d}$. $\mathrm{m}$.). The FA developed in flour of pearl millet was approximately 2 and 5 fold higher than that in flour of maize and wheat respectively. These results are consistent with Rehman (2006) who reported increase in fat acidity of wheat and maize during storage at 10, 25 and $45{ }^{\circ} \mathrm{C}$ for 6 months. Increase in FA of pearl millet flour stored for different time periods has been reported by many investigators (Nantanga et al., 2008; Yadav et al., 2012; Čepková et al., 2014; Tiwari et al., 2014). Built up in fat acidity during storage is mainly due to action of lipases, causes bitterness and can make meal unacceptable (Tiwari et al., 2014). Lipase activity is not distributed in the whole grain, but is confined to the aleurone layer and emryonic tissues, where lipids are metabolized. The milling of grains leads to tissue damage and contact between enzymes and the fat substrate increases (Dvoracek et al., 2010).

$\mathrm{pH}$ is an important parameter in determining quality of flour and low $\mathrm{pH}$ value imparts sour taste to the flour which makes it less preferred for consumption (Apea Bah et al., 2011). Decreases in differences in $\mathrm{pH}$ of water extract of flour of these cereals were apparent (Figure 1b). Decrease in $\mathrm{pH}$ equivalent to 0.40 was recorded in extract of pearl millet flour compared to change of only 0.10 and 0.23 was detected in that of wheat and maize respectively after 30 days of storage. These results are in agreement with those of Daramola et al. (2010) and Agu et al. (2014) who reported gradual decrease in the $\mathrm{pH}$ values of pupuru flour and instant dambu (prepared from pearl millet) samples as the storage time increased. A significant decrease in $\mathrm{pH}$ with increase in storage temperature and period was observed during storage of wheat flour (Akpe et al., 2010). Similarly decrease in the $\mathrm{pH}$ value of unmalted maize after 12 weeks of storage period was reported by Adetuyi et al. (2009). Most likely there is increase in the content of organic acids other than fatty acids since these are not extracted in water. Formation of acidic chemical constituents as a result of enzymatic action might be one of the possible reasons for decreased $\mathrm{pH}$ after 30 days of storage of flour.

Enzymatic activities: The changes which occur in stored flour are probably due to enzymes produced or
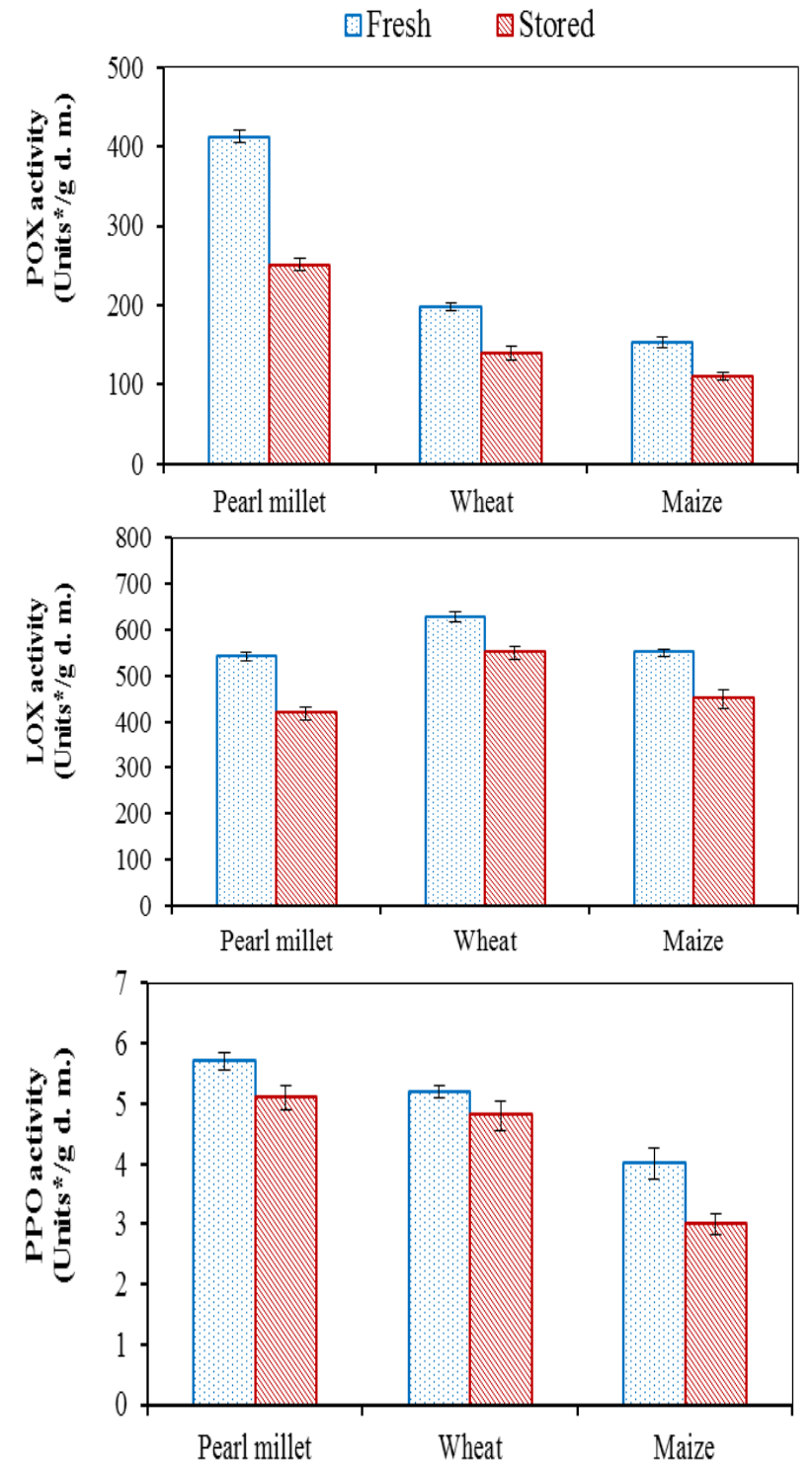

Fig. 2. $P O X(a), L O X(b)$ and $P P O$ (c) activity of fresh and stored flour of pearl millet, wheat and maize. Values are mean $\pm S E, n=3$, *One unit is equal to 0.1 change in O.D./ $\min$.

liberated in the flour. Activity of POX in fresh and stored flour (at $15{ }^{\circ} \mathrm{C}$ and $82 \% \mathrm{RH}$ ) of these cereals grains has been compared and presented in Fig. 2a. Fresh flour of pearl millet had 413 units/g d. m. of POX activity while that of wheat and maize had only 198 and 153 units/g d. m. of the activity, respectively. Substantial decrease in activity of POX was observed upon storage of these three kinds of flour. The level of activity of POX in flour declined by a margin of $39 \%$ (from 413 to 251 units/g d. m.) in pearl millet, by $29 \%$ (from 198 to 140 units/g d. m.) and $28 \%$ (from 153 to 110 units/g d. m.) in wheat and maize, respectively. Thus, even after decrease activity of the POX was higher in flour of pearl millet in comparison to wheat and maize. Bangar et al. (1999) reported that water soluble phenolics and peroxidase activity concentrated 
mostly in the germ fraction of the grain appeared to be responsible for odour generation in stored pearl millet meal. Peroxidase like most heme proteins catalyzes the non-enzymatic, peroxidative degradation of unsaturated fatty acids yielding volatile and flavourful carbonyl compounds that may contribute to oxidized flavour (Richardson and Hyslop, 1985).

Lipoxygenase is considered as one of the factor responsible for the deterioration of corn flour during storage (Orak et al., 2010). Comparison of pearl millet with wheat and maize in terms of LOX activity is depicted in Figure 2b. Activity of LOX was found to be highest in fresh flour of wheat (628 units/g d. m.) and almost similar (550 and 541 units/g d. m) in maize and pearl millet. It implies that LOX was not directly involved in flour deterioration because it is well known that shelf life of pearl millet flour was lowest in comparison to wheat and maize. While Mandal et al. (2014) reported that in soybean the major culprit of untoward flavour development is a lipoxygenase catalyzed oxidation reaction. Upon storage maximum fold decrease in LOX activity was recorded in pearl millet followed by maize and wheat respectively. Similarly decrease in activity of lipoxygenase was reported by Ramezanzadeh et al. (1999) in rice bran during 16 weeks of storage.

The oxidation of phenolic compounds present in the plant tissues by PPO enzymes leads to the formation of undesired brown pigments and off-flavoured products (Yemenicioglu et al., 1999). To find out role of PPO in determining quality of flour its activity is determined in fresh and stored flour (Fig. 2c) of pearl millet, wheat and maize. PPO activity was found to be similar in fresh flour of pearl millet (5.7 units/g d. m.) and wheat (5.2 units/g d. m.) while fresh flour of maize possesses lowest PPO activity (4.0 units/g d. m.). Fold decrease in PPO activity was almost similar in pearl millet (1.1 fold), wheat (1.1 fold) and maize (1.3 fold) after 30 days of storage. According to Richardson and Hyslop (1985), decrease in enzyme activity during storage may be due to a change in the stability of enzyme conformers, increased intra-enzymic hydrogen bonding or decreased accessibility of enzyme to substrate. It could also be due to increased hydrogen bonding between water and either substrate or enzyme active site, formation of enzyme polymers, changes in mechanism, shift in $\mathrm{pH}$ or increased in viscosity.

\section{Conclusion}

Quality of cereal grains flour was adversely affected as a result of storage. It is well known that shelf life of pearl millet flour was lowest in comparison to wheat and maize. It was clear from the data that increase in FA (287.5 mg KOH/g d.m.), decrease in $\mathrm{pH}(0.4)$ and activity of POX (413 Units/g d.m.) was very high in pearl millet as compared to wheat $(61 \mathrm{mg} \mathrm{KOH} / 100 \mathrm{~g}$ d.m., 0.1, 198 Units/g. d.m. respectively) and maize
(151 mg KOH/100 g d.m., 0.23, and 153 Units/g d.m. respectively) while activity of LOX and PPO was found to be comparable in either pearl millet and maize or pearl millet and wheat respectively. In view of these facts, it is suggested that FA, $\mathrm{pH}$ of water extract of flour and POX activity might be used as biochemical markers to determine shelf life of flour.

\section{ACKNOWLEDGEMENTS}

The corresponding author is highly thankful to Department of Science and Technology, Govt. of India for providing financial assistance in the form of INSPIRE fellowship (SRF). The authors are also grateful to Chaudhary Charan Singh Haryana Agricultural University, Hisar for providing all the facilities required during the course of investigation.

\section{REFERENCES}

Adetuyi, F. O., Badezo, O. F., Ikujenlola, A. V. and Onosuli, S. V. (2009). Storage influence on the functional properties of malted and unmalted maize (Zea mays L ssp mays) and soyabean (Glycine max L Merrill) flour blends. Afr. J. Food Sci., 3: 056-060

Agu, H., Badau, M., Usman. A. and Jideani, V. (2014). Effects of steaming duration and preservation on storage stability of pearl millet based instant Dambu. Aust. J. Eng. Res., 1: 50-60

Akpe, A. R., Usuoge, P. O. A., Enabulele, O. I., Esumeh, F. I. and Obiazi, H. A. (2010). Bateriological and physicochemical quality of wheaten white bread flour made for nigerian market. Pak. J. Nutr., 9: 1078-1083

AACC (1999). Method 02-03A. Approved methods of the American Association of Cereal Chemists. American Association of Cereal Chemists, St. Paul, Minn.

AOAC (1990). Method 943.02. Official methods of analysis. Association of Official Analytical Chemists, Washington, D.C.

Apea-Bah, F. B., Oduro, I., Ellis, W. O. and Safo-Kantanka, O. (2011). Factor analysis and age harvest effect on the quality of flour from four cassava varieties. World $J$. Dairy Food Sci., 6: 43-54

Bangar, M. U., Bhite, B. R., Kachare, D. P. and Chavan, J. K. (1999). Role of phenolics and polyphenol oxidizing enzymes in odour generation in pearl millet meal. $J$. Food Sci. Technol., 36: 535-537

Čepková, P. H., Dvořáková, Z., Janovská, D. and Viehmannová, V. (2014). Rancidity development in millet species stored in different storage conditions and evaluation of free fatty acids content in tested samples. $J$. Food Agric. Environ., 12: 101-106

Dahuja, A. and Madaan, T. R. (2003). Estimation of parameters responsible for the generation of off-flavour in some Indian varieties of soybeans. Plants Food Hum. Nutr., 58: 1-8

Daramola, O. A., Idowu, M. A., Atanda, O. O. and Oguntona, C. R. B. (2010). Effects of packaging material on the quality of "pupuru" flour during storage. Afr. J. Food Sci., 4: 258-263

Dobaldo-Maldonado, A. F., Pike, O. A., Sweley, J. C. and Rose, D. J. (2012). Key issues and challanges in whole wheat flour milling and storage. J. Cereal Sci., 56: 119- 
126

Dvoracek, V., Janovska, D., Papouskova, L. and Bicanova, E. (2010). Post harvest content of free titrate acids in the grains of proso millet varieties (Panicum milliaceum L.) and changes during grain processing and storage. Czech J. Genet. Plant Breed, 46: S90-S95

Goyal, P. and Chugh, L. K. (2014). Partial purification and characterization of peroxidase from pearl millet [Pennisetum glaucum (L.) R. Br.] grains. J. Food Biochem., 38: 150-158

Huyghcbact, G. and Schoner, F. J. (1999). Influence of storage and addition of enzyme on metabolizable energy content of wheat. Arch. Gefluegelkd., 63: 13-20

Kurger, J. E. (1976). Changes in the polyphenol oxidases of wheat during kernel growth and maturation. Cereal Chem., 53: 201-213

Lee, Y.C. and Hammes, J.K. (1979). Heat inactivation of peroxidase in corn on the cob. J. Food Sci., 44:785-787.

Malik, C. P. and Singh, S. B. (1980). Plant enzymology and histoenzymology. Kalyani Publishers, New Delhi, India.

Mandal, S., Dahuja, A., Kar, A. and Santha, I. M. (2014). In vitro kinetics of soybean lipoxygenase with combinatorial fatty substrates and its functional significance in off flavour development. Food Chem., 146: 394-403

Nantanga, K. M. K., Seetharaman, K., Kock, Lde. H. and Taylor, R. N. J. (2008). Thermal treatements to partially pre-cook and improve the shelf life of whole pearl millet flour. J. Sci. Food Agric., 88: 1892-1899

Orak, H. H., Baser, I., Korkut, K. Z., Bilgin, O. and Orak, A. (2010). Investigations of peroxidase and lipoxygenase enzyme activities of dent corn (Zea mays L.) hybrids and their relationships with colour and chemical characteristics. J. Agro Crop Sci., 1: 33-40

Ramezanzadeh, F. M., Rao, R. M., Windhauser, M., Prinyawiwatkul, W. and Marshall, W .E. (1999). Prevention of oxidative rancidity in rice bran during storage. $J$. Agric. Food Chem., 47: 2997-3000

Rehman, Z. U. (2006). Storage effects on nutritional quality of commonly consumed cereals. Food Chem., 95:53-57.

Richardson, T. and Hyslop, D. B. (1985). Enzymes. Food Chemistry, Marcel Dekker, Inc. New York Pp. $371-476$

Surrey, K. (1964). Spectrophotometric determination of lipoxidase activity. Plant Physiol., 39: 65-70

Suzuki, T., Honda, Y., Mukasa, Y. and Kim, S. J. (2006). Characterization of peroxidase in buckwheat seed. Phytochemistry, 67: 219-224

Tiwari, A., Jha, S. K., Pal, R. K., Sethi, S. and Krishan, L. (2014). Effects of pre-milling treatments on storage stability of pearl millet flour. J. Food Process. Preserv., 38: 1215-1223

Wang, L. and Flores, R. A. (1999). The effects of storage on flour quality and baking performance. Food Rev. Int., 15: $215-234$

Yadav, D. N., Anand, T., Kaur, J. and Singh, A. K. (2012). Improved storage stability of pearl millet flour through microwave treatment. Agric. Res., 1: 399-404

Yemenicioglu, A., Ozkan, M. and Cemeroglu, B. (1999). Some characteristics of polyphenol oxidase and peroxidase from Taro (Colocasia antiquorum). Turkey J. Agric. Forestry, 23: 425-430 